\title{
Salmonella enterica in the chicken: how it has helped our understanding of immunology in a non-biomedical model species
}

\author{
Paul Wigley* \\ Department of Infection Biology, School of Veterinary Science and Institute for Infection and Global Health, University of Liverpool, Liverpool, UK
}

\author{
Edited by: \\ Adam Cunningham, University of \\ Birmingham, UK \\ Reviewed by: \\ Xun Suo, China Agricultural \\ University, China \\ Ranjit Kumar, University of \\ Birmingham at Alabama, USA \\ *Correspondence: \\ Paul Wigley, Department of Infection \\ Biology, School of Veterinary Science \\ and Institute for Infection and Global \\ Health, University of Liverpool, \\ Leahurst Campus, Neston CH64 7TE, \\ UK \\ e-mail: paul.wigley@liv.ac.uk
}

\begin{abstract}
Salmonella infection of the chicken is important both as a source of foodborne human salmonellosis and as a source of disease in the chicken itself. Vaccination and other control strategies require an understanding of the immune response and as such have been important in understanding both mucosal immunity and more generally the response to bacterial infection. In this review, we discuss the contribution the study of avian salmonellosis has made to understanding innate immunity including the function of phagocytic cells, pattern recognition receptors, and defensins. The mucosal response to Salmonella infection and its regulation and the contribution this makes in protection against infection and persistence within the gut and future directions in better understanding the role of $\mathrm{T}_{H} 17$ and Tregs in this response. Finally, we discuss the role of the immune system and its modulation in persistent infection and infection of the reproductive tract. We also outline key areas of research required to fully understand the interaction between the chicken immune system and Salmonella and how infection is maintained in the absence of substantive gastrointestinal disease.
\end{abstract}

Keywords: Salmonella, chickens, innate immunity, adaptive immune responses, immune regulation, heterophils, toll-like receptors, mucosal immune system

\section{INTRODUCTION}

Salmonella enterica has a close relationship with the chicken, as poultry meat and eggs are regarded as the most important source of human foodborne infection (1). Furthermore, host-adapted serovars of Salmonella are important worldwide pathogens of the chicken causing the fowl typhoid and pullorum disease (2). As a consequence, $S$. enterica is the most studied bacterial pathogen in the chicken, not as in the case of the mouse and other biomedical models to determine the mechanisms of infection and immunity related to human disease, but with a specific focus on its control in the poultry industry. As such the development of vaccines and potential immunotherapeutic agents and studies based on understanding the transmission and carriage of Salmonella have been critical to our understanding of the function of the avian immune system.

Avian salmonellosis can be broadly divided into two main types based on infection biology. The majority of broad-host range $S$. enterica serovars are capable of infecting the chicken, usually leading to a period of colonization of lower gastrointestinal tract. In some serovars, notably $S$. Typhimurium and $S$. Enteritidis, this may be accompanied by a low-level systemic infection that is resolved through cellular immunity within two-to-three weeks $(3,4)$. Colonization is usually accompanied by activation of inflammatory responses in the ileum and the two large blind caeca that branch off at the junction of the colon and ileum $(5,6)$. Although infection with these serovars can lead to systemic disease in chicks or immunocompromised animals, in healthy immunocompetent animals of a week of age or more, infection leads to little or no signs of disease. In contrast are the two adapted serovars $S$. Gallinarum, the cause of fowl typhoid, and $S$. Pullorum, the cause of Pullorum disease (2). These serovars lead to a systemic infection, often with high levels of morbidity and mortality (7) Unlike the broad-host range serovars invasion via the gut is not accompanied inflammation allowing the establishment of systemic infection while avoiding activation of immunity $(6,8,9)$. This avoidance of innate activation has been termed "stealth infection" and is also employed by Salmonella Typhi in human beings (10). Colonization of the gut by avian-adapted serovars is also poor, largely as a consequence of "functional genomic shrinkage" with the loss of genes or accumulation of pseudogenes leading to a reduced metabolic capacity forcing them into a systemic intracellular lifestyle (11). As in mammalian models of infection, Salmonella invade and persist within macrophages and dendritic cells, and, as in mice, the progression of infection is to a large extent dependent on the susceptibility of the animal (9). In experimental fowl typhoid in a susceptible chicken, infection rapidly becomes disseminated leading to septicemia (5). In resistant animals, infection is better controlled by macrophages and eventually cleared via adaptive responses. S. Pullorum is generally a less virulent pathogen of the chicken, but can lead to a persistent systemic infection or carrier state that can in turn lead to infection of the mature reproductive tract of the hen (12). The stages of infection in avian salmonellosis and interactions with the immune systems are summarized in Figure 1.

The diversity of interactions with the host by S. enterica in the chicken, in both in terms of the tissues and cell types involved and the steps taken by the bacterium to avoid and manipulate the 


\begin{tabular}{|c|c|c|}
\hline $\begin{array}{l}\text { Infection via faecal-oral route } \\
\text { - Attachment and invasion of } \\
\text { intestinal epithelium } \\
\text { Activation of innate immune } \\
\text { response through action of } \\
\text { bacterial effector proteins and } \\
\text { host recognition (TLR } 4,5 \text { \& } \\
21 \text { ) } \\
\text { Pro-inflammatory CXC } \\
\text { chemokine response leads to } \\
\text { influx of heterophils } \\
\text { Damage to intestinal } \\
\text { epithelium but activation of } \\
\text { response } \\
\text { Host-adapted serovars (S. } \\
\text { Gallinarum \& S. Pullorum) } \\
\text { invade via 'stealth' infection- } \\
\text { little or no activation of innate } \\
\text { response } \\
\text { Absence of flagella in adapted } \\
\text { serovars avoids TLR5 } \\
\text { recognition \& targeting of } \\
\text { lymphoid tissue (caecal } \\
\text { tonsils) }\end{array}$ & $\begin{array}{l}\text { Systemic response } \\
\text { - } \quad \text { Translocation to spleen and liver } \\
\text { Establishment of intracellular } \\
\text { infection in macrophages } \\
\text { Macrophage activation and } \\
\text { antimicrobial activity related to } \\
\text { genetic resistance encoded by SAL1 } \\
\text { locus } \\
\text { Initiation of cellular response-key } \\
\text { role in IFN- } \gamma \text { by } \gamma \delta \mathrm{T} \text { cells } \\
\text { Immunomodulation though up- } \\
\text { regulation of } \mathrm{T}_{\mathrm{H}} 2 \text { response by avian } \\
\text { adapted serovars } \\
\text { Development of IgM and IgY } \\
\text { antibody response }\end{array}$ & $\begin{array}{l}\text { Clearance } \\
\text { - Systemic clearance at 2-4 weeks } \\
\text { post infection by both cellular and } \\
\text { antibody responses } \\
\text { - Intestinal clearance } 3-12 \text { weeks } \\
\text { dependent on } T_{H} 1 \text { response } \\
\text { - Depletion of antibody through } \\
\text { bursectomy has no effect on } \\
\text { clearance }\end{array}$ \\
\hline Initial Infection & Establishment of Infection & Outcome \\
\hline
\end{tabular}

FIGURE 1 | A summary of the major interactions between Salmonella enterica and the chicken immune system. During avian salmonellosis initial interactions between pathogen and host innate immunity occur in the intestinal epithelium. Progression of infection and the related immune response is related to the infecting serovar or strain and to the host-genetic background. Salmonella is frequently invasive in chickens leading to both systemic and mucosal responses. Typically, in resistant animals systemic infection is transient and cleared by the adaptive immune response. However, in susceptible animals where macrophages fail to limit infection, a disseminated infection resulting in death can occur. Clearance from the intestinal tract may take a number of months and is associated with cellular responses. Systemic persistence leading to a carrier state may occur, in particular with $S$. Pullorum with bacteria persisting in low numbers for the lifetime of the bird. immune system has revealed many similarities between the mammalian and avian systems that broadly function in the same way when challenged by Salmonella, yet there are a number of, sometime subtle, differences that reflect 200 million years of divergent evolution.

\section{MAJOR DIFFERENCES BETWEEN THE AVIAN AND MAMMALIAN IMMUNE SYSTEMS - A BRIEF OVERVIEW OF A COMPACT IMMUNE SYSTEM}

Functionally the immune system of the chicken behaves much the same way as that of mammals, perhaps reflecting a common ancestry. "Chickens are not feathered mice." a comment made by Jim Kaufman, a leader in the field of avian immunogenetics, clearly illustrates that there are key structural and functional differences found between the classes. Generally, the chicken immune system is more compact, with less polymorphism in its receptors and all but the IL-15 multigene family having fewer members than its murine equivalent. This is perhaps most clearly illustrated by the MHC Class I of the chicken, which has only two alleles with one dominantly expressed, leading to it being termed the "minimal essential MHC" (13). The chicken has only three immunoglobulin classes IgG (or IgY), IgM, and IgA and no IgG subclasses.
Although the chicken TCR is considered to be less polymorphic there are two variants of $\alpha \beta$ T-cells termed TCR 1 and TCR 2 along with $\gamma \delta$ cells, which, interestingly, are found in greater numbers in the chicken. Toll-like receptors also have the same broad structure and function as mammals and recognize a similar array of ligands, though differences are found perhaps most markedly the absence of TLR9, which is replaced functionally by TLR21 (14), and the presence of TLR15, which has no known equivalent in mammalian systems (15). A comprehensive description of the avian immune system can be found in the recently published 2 nd edition of 'Avian Immunology' (16).

\section{INTERACTION WITH THE INNATE IMMUNE SYSTEM - INFORMING PHAGOCYTE FUNCTION, INFLAMMATION, AND TOLL-LIKE RECEPTORS}

Salmonella usually infects chickens via the fecal-oral route with spread from the intestinal tract primarily at the distal ileum and caeca of the bird (1). Invasion is an inflammatory process leading to expression of proinflammatory cytokines and the chemokines CXCLi1 and CXCLi2, considered the equivalent of mammalian IL-8 $(5,6,17,18)$. This in turn leads to an influx of heterophils and monocytic phagocytes to the gut resulting in inflammation 
and damage to the gut including fusion and flattening of the villi. Despite this enteropathogenic response, diarrheoa rarely occurs. While the bacterium itself induces cellular changes and inflammation through secreted effectors via its SPI1 Type III secretion system, recognition of flagellin through TLR5 appears to be the key event in the process (19). This is well illustrated by the fact that the non-flagellate avian-adapted serovars cause little inflammation during epithelial invasion in vitro or in vivo $(9,20)$, and that mutations in the flagellin gene of Salmonella Typhimurium lead to a more rapid invasion with lower initial levels of inflammatory signal $(9,19,20)$. Indeed, this may be an evolutionary feature of adaptation to the avian host.

The consequence of activation of innate immunity is an influx of heterophils, the avian polymorphonuclear cell, and macrophages to the intestine. While these can lead to inflammatory damage, they also largely limit invasive disease. Our understanding of the biology and function of heterophils is almost entirely based on Salmonella infection studies. Depletion of heterophils changes $S$. Enteritidis from a gastrointestinal infection to a systemic infection illustrating their critical role in early immunity (21). Heterophils possess an array of TLRs (22), are efficient phagocytes, and can produce extracellular traps to facilitate this process (23). Unlike mammalian neutrophils, heterophils rely more on antimicrobial peptides as a bacterial killing mechanism (24) and although they produce nitric oxide and oxidative responses to Salmonella they lack the myeloperoxidase pathway (25). The study of the interaction of Salmonella with primary cultures of heterophils along with primary and continuous macrophage lines has been critical in our understanding of pattern recognition receptors in the chicken, including TLR5 as described above. Perhaps this is most clearly seen for TLR 4 where variation in macrophage responses to $S$. Typhimurium challenge has identified both differences in levels of TLR4 expression and polymorphism in the receptor sequences between chicken lines. This suggests that responsiveness to LPS in chicken, which is frequently much lower than in mammals, is governed by variation in both levels of expression of the receptor and in the structure of the receptor itself $(26,27)$. Chicken TLR21 has no mammalian equivalent, though functionally it mirrors mammalian TLR9 in recognition of unmethylated (or CpG) DNA sequences. Much of our understanding of the response to $\mathrm{CpG}$ motifs has come through attempts to develop these sequences as immunostimulatory molecules or as vaccine adjuvant components to help control Salmonella $(28,29)$, although identification of the role of TLR21 was also founded in understanding the response to Campylobacter jejuni (14).

Macrophages differ little in structure or function to mammals, displaying a range of TLRs, expression of MHC Class II and phagocytic and antimicrobial activity. It is not yet understood whether avian macrophages have M1 or M2 phenotypes. The interaction with macrophages and dendritic cells and Salmonella is a key stage in the progression of systemic infection in particular. We have previously reviewed this in some detail (9), so will only briefly cover the essential points here. The use of inbred chicken models has identified the genetic locus SAL1 that displays a phenotype of resistance to systemic salmonellosis (30). Macrophages derived from such birds shown enhanced oxidative killing and more rapid expression of key inflammatory and $\mathrm{T}_{\mathrm{H}} 1$-assocated cytokines $(31,32)$. Fine mapping of this resistance locus has identified Akt1, a protein kinase, and Siva, a CD27-binding protein as functional candidates for the SAL1 locus (33). A number of chicken macrophage-like cell lines are available and these have been utilized extensively to understand the interactions between Salmonella and this cell type in terms of cytokine response, the role of the bacterial SPI2 type III secretion system in intracellular survival and antimicrobial response to a range of serovars and have largely shown a common biology between mammalian and avian species (34-40).

As mentioned previously antimicrobial peptides play a key role in protection against avian salmonellosis. $\beta$-Defensins termed gallinacins in the chicken are produced by a range of cells and tissues in response to Salmonella infection or vaccination including, but not restricted to gallinacins $2-5$ and 7 in gut epithelium (41-43). Gallinacins are also expressed during reproductive tract infection as described below. Like their mammalian equivalents gallinacins are cysteine-rich antimicrobials that have been shown to be active against a range of Gram negative and Gram positive bacterial species and have been considered as potential therapeutics in human medicine (44). Cathelicidins, also termed fowlcidins in the chicken, have also been described, but their role in salmonellosis is not known $(44,45)$. Other innate factors including increased expression of mucins, and in particular the gel-forming mucins (Muc2, Muc5ac, Muc5b, and Muc6), are likely to play a role in maintaining the epithelial barrier and limiting infection. Purified chicken mucin has been shown to have activity against Campylobacter (46), and work is ongoing in out laboratory to determine its role in enteric infections.

\section{THE ADAPTIVE RESPONSE TO INFECTION AND THE SUCCESS OF VACCINATION}

The success of vaccination programs such as those employed in the UK to reduce the burden of foodborne salmonellosis through control in egg and latterly poultry meat production is a clear indicator that protective adaptive immune responses can be elicited in the chicken (47). Infection with Salmonella elicits both antibody and cellular responses that can be detected from around a week post-infection. Clearance of both $S$. Enteritidis and the attenuated $S$. Gallinarum 9R vaccine strain from the spleen and liver is at around 2-3 weeks post-infection which coincides with high levels of interferon- $\gamma$ expression and also production of IgM and IgG antibodies $(5,7,48,49)$. Preliminary adoptive transfer experiments have shown partial protection to systemic infection can be achieved by transfer of T lymphocytes (9).

In contrast, clearance from the intestinal tract is a much slower process. Salmonella infection leads to production of secretory IgA in the gut but any protective role is unclear as studies employing bursectomised (B lymphocyte-free) chickens give differing results dependent on the method employed. Both clearance and protection to re-challenge with Salmonella are reduced when hormonal or cyclophosphamide are used to deplete the Bursa of Fabricius $(50,51)$, whereas surgical bursectomy in ovo has no effect on the clearance of Salmonella or protection to re-challenge (52). Whilst the latter study suggests antibody is not required for clearance, the success of inactivated vaccines in Salmonella control in the chicken does suggest it plays an important role. However a number 
of studies have shown that challenge elicits a strong Th1 response and that cellular immunity is more important in the chicken and clearance is dependent on age and cellular development. What we do not yet know is which effector mechanisms are employed in clearance. We do have some understanding of how the cellular response is activated. $\gamma \delta$-T lymphocytes are found in greater numbers in the chicken gut than mammalian systems and these cells play a key role in activation of adaptive response in the caeca and ileum. Salmonella challenge results in an influx of $\gamma \delta$ lymphocytes and expression of IFN- $\gamma$, IL-12, and IL-18 leading to activation of $\mathrm{T}_{\mathrm{H}} 1$ responses $(53,54)$. The $\gamma \delta$ lymphocyte population has a heterogenous structure and phenotype in the chicken, with association of subsets with particular tissues (55). In the caeca, the $\mathrm{CD}^{+} \alpha \alpha^{+} \gamma \delta$ population is thought to be the main activator of the adaptive response (56).

\section{MUCOSAL RESPONSES AND THE ROLE OF AND Tregs AND $\mathrm{T}_{\mathrm{H}} 17$ CELLS}

Given the importance of $\mathrm{T}_{\mathrm{H}} 17$ cells in the mucosal inflammatory response, and as sentinels in the intestinal epithelium in mammals, there has been little focus on their role in avian salmonellosis. Furthermore, our understanding of the regulation of inflammatory responses and the role of regulatory $\mathrm{T}$-cells in maintaining gut integrity following inflammatory responses is also limited. $\mathrm{T}_{\mathrm{H}} 17$ cytokines are elicited rapidly after infection in the bovine ligated ileal loop Salmonella infection model (57), probably through stimulation of non-specific $\mathrm{T}_{\mathrm{H}} 17$ cells while Salmonella-specific $\mathrm{T}_{\mathrm{H}} 17$ cells possibly recognizing flagellin following activation via TLR5dependent pathways may also contribute to intestinal mucosal protection (58). In the chicken IL-17 expression is upregulated in the cecum, the main site of bacterial colonization, following $S$. Enteritidis challenge though as yet no functional rule has been ascribed (42). Currently, the role of IL-17 is best characterized during infection by species of the chicken intestinal apicomplexan protozoan Eimeria where IL-17 may play a role both in protection and pathology dependent on the Eimeria species and co-infection with other enteric pathogens such as Clostridium perfringens (59-62).

The fact that many Salmonella serovars persist within the chicken intestinal tract with little sign of gastrointestinal disease despite eliciting a considerable inflammatory response and that inflammatory responses to Salmonella are relatively shortlived (5) strongly suggests there is a degree of regulation of this response. Our recent work on invasive Salmonella Typhimurium ST313 in the chicken illustrates this clearly (63); there is an initial CXCLi1 and CXCLi2 response leading to intestinal damage at three days post-oral infection, but by seven days post-infection this response is lowered and inflammatory damage largely resolved despite bacterial persistence (63). Some years ago, we showed that the lowering of intestinal proinflammatory signals following colonization with $S$. Typhimurium corresponded to increased expression of TGF- $\beta$, suggesting that regulation of inflammation was taking place (5). More recently the expression of IL-10 has been shown in the cecal tonsils in birds infected with $S$. Enteritidis at 4 days post-infection but not following infection the non-inflammatory avian-adapted serovars. It would seem likely that regulation of inflammatory immune responses, presumably by regulatory T-cells, allow Salmonella to persist within the gut for a number of weeks without disease to the bird but that the initial inflammatory response is sufficient to help control invasion and elicit responses that lead to systemic and eventually clearance of gastrointestinal infection. Such a "tolerogenic" response would have little or no impact on the bird itself, but has public health consequences in allowing persistence for several weeks, particularly given broiler chickens are typically slaughtered at around 6 weeks of age.

Recently, $\mathrm{CD} 4{ }^{+} \mathrm{CD} 25^{+}$cells have been identified as the avian equivalent of the mammalian Tregs, though the chicken appears to lack an ortholog of FoxP3 that are a characteristic feature of mammalian Tregs. Chicken $\mathrm{CD} 4{ }^{+} \mathrm{CD} 25^{+}$cells produce both IL-10 and TGF- $\beta$ family cytokines and suppress T-cell proliferation in vitro. Stimulation of $\mathrm{CD} 4{ }^{+} \mathrm{CD} 25^{+}$in vitro or in vivo with Salmonella LPS, or infection, increases suppressive active. Intriguingly, $\mathrm{CD} 4{ }^{+} \mathrm{CD} 25^{+}$have also been shown to traffic to the cecal tonsil, suggesting this lymphoid organ at the ileal-cecal junction may play a key role in regulating intestinal immunity. There is clearly considerable scope to improve our understanding of chicken Tregs including the interaction with the intestinal microbiota, enteric pathogens, and in homeostasis of the healthy gut. Therapeutic approaches to deplete Treg function and thereby reduce suppression of the response to Salmonella have been proposed to reduce the carriage of Salmonella or Campylobacter. However, such an approach may well be detrimental to the health and welfare of chickens, leading to dysregulation of regulation of responses to the intestinal microflora resulting in poor gut health. Such an approach could also lead to uncontrolled inflammatory responses to Salmonella or Campylobacter infection leading to intestinal damage and diarrhea.

\section{IMMUNOMODULATION IN PERSISTENT INFECTIONS}

A feature of avian salmonellosis is persistent infection or carrier state. Intestinal carriage may occur for several months following infection with broad-host range serovars such as $S$. Typhimurium and $S$. Enteritidis, whereas avian-adapted serovars, most notably $S$. Pullorum, may persist in low numbers within macrophages in the liver and spleen for the lifetime of the animal. This persistence is in the face of a substantial immune response requiring evasion or modulation of the response by the bacterium. As discussed above immune clearance in the chicken is likely to be centered on $\mathrm{T}_{\mathrm{H}}$ 1-based cellular responses so avoiding these responses is key to pathogen survival. S. Pullorum is protected from antibody responses due to its intracellular niche, yet infection is associated with production of high titer IgG responses (12). Using a comparative approach between $S$. Pullorum and its close relative $S$. Enteritidis, we were able to show that systemic clearance of the latter was associated with a cellular response (9). In contrast, $S$. Pullorum infection leads to increased expression of IL-4 but unlike $S$. Enteritidis little expression of IFN- $\gamma$. This bias toward a $\mathrm{T}_{\mathrm{H}} 2$ response would allow $S$. Pullorum to establish an intracellular carrier state avoiding $\mathrm{T}_{\mathrm{H}} 1$-mediated clearance.

The mechanisms that underlie persistence in the GI tract are harder to determine. While as discussed above, regulation of the inflammatory response may help the establishment of a persistent infection, there is usually immune clearance in the long term. 
As with systemic infection, the level and length of intestinal colonization is influenced by the generic background of the host. A recent study using inbred White Leghorn chickens of Line $6_{1}$ considered susceptible to Salmonella colonization and Line $\mathrm{N}$ considered resistant (4), used a genome-wide transcriptional approaches to look at variations in enterocyte gene expression in an established GI tract infection (64). Both lines showed evidence of down-regulation of $\mathrm{T}_{\mathrm{H}} 1$ responses, little evidence of stimulation of the $\mathrm{T}_{\mathrm{H}} 17$ pathway, and no difference in expression of regulatory cytokines including IL-10 and TGF- $\beta$. In contrast the $6_{1}$ susceptible line showed enhanced expression of key $\mathrm{T}_{\mathrm{H}} 2$ cytokines including IL-4 and IL-13. This supports the notion that immune clearance of avian salmonellosis in $\mathrm{T}_{\mathrm{H}} 1$ dominated and that $\mathrm{T}_{\mathrm{H}} 2$ responses are associated with carrier states. As indicated by the authors, this is parallel with the murine model of $S$. Typhimurium where persistence is favored in M2 macrophage phenotypes that are driven by $\mathrm{T}_{\mathrm{H}} 2$ cytokine responses.

\section{INFECTION AND THE IMMUNE RESPONSE IN THE REPRODUCTIVE TRACT}

A unique feature of avian salmonellosis is the frequent infection of the female reproductive tract and transmission to eggs by $S$. Enteritidis and S. Pullorum $(12,65)$. The structure and function of the immune system of the avian reproductive has been recently reviewed, reflecting the considerable progress in our understanding of its structure and function made in the last few years (66). Infection by Salmonella or stimulation with LPS results in a local innate response and in particular secretion of gallinacins throughout the reproductive tract, but in particular the lower part of the oviduct and uterus (67-69). There is also an organized T lymphocyte structure in the developing tract and IL-4 expressed within the tract that can lead to specific IgA responses. Sexual maturity in the hen has a profound effect on both systemic and local lymphocyte populations with a temporary fall in circulating $\mathrm{T}$ lymphocytes and particular $\mathrm{CD}^{+}$cells and a loss of lymphocytic structure in the reproductive tract (70). This results in increased susceptibility to Salmonella challenge and decreased efficacy of vaccination at the start of the egg-laying period.

\section{CONCLUSION AND FUTURE DIRECTIONS}

Avian immunology has advanced greatly in recent years with the advent of genomic and transcriptomic approaches overcoming many of the difficulties due to lack of reagents, transgenic animals, or differences in the immune system that prevent the use of techniques commonly used in human and murine immunology. As transgenic chickens are now becoming available, functional studies on knockout chickens will no doubt follow. Nowhere will these be more welcomed than in understanding mucosal immunity, the "business end" of the response to Salmonella. There are a number of key questions that still need to be fully answered:

1. What are the mechanisms that underlie persistence of Salmonella in the chicken gut?

2. What regulates the GI response to prevent excessive intestinal damage?

3. Which effector mechanisms are important in clearance?
In addition to these, there are a number of areas, not least the role of microbiota in the development and homeostasis of the chicken mucosal immune system that require much work to improve our understanding of fundamental processes and mechanisms. While the ultimate aim of the avian Salmonella immunologist is to develop and improve vaccination and other controls that reduce the burden of Salmonella in food production, a better understanding of how the chicken regulates its response is as important, as disruption of this may have implications for the health and welfare of the animal itself, something that is increasingly important to the consumer.

\section{ACKNOWLEDGMENTS}

The author wishes to thank Dr. Suzanne Humphrey and Dr. Lizeth LaCharme-Lora for their assistance. Avian Immunology research in the author's laboratory is supported by the Biotechnology and Biological Science Research Council (Grant Numbers BB/J017353/1, BB/J008249/1, and BB/D007542/1).

\section{REFERENCES}

1. Barrow PA, Jones MA, Smith AL, Wigley P. The long view: Salmonella - the last forty years. Avian Pathol (2012) 41:413-20. doi:10.1080/03079457.2012.718071

2. Barrow PA, Freitas Neto OC. Pullorum disease and fowl typhoid - new thoughts on old diseases: a review. Avian Pathol (2011) 40:1-13. doi:10.1080/03079457. 2010.542575

3. Beal RK, Powers C, Wigley P, Barrow PA, Smith AL. Temporal dynamics of the cellular, humoral and cytokine responses in chickens during primary and secondary infection with Salmonella enterica serovar Typhimurium. Avian Pathol (2004) 33:25-33. doi:10.1080/03079450310001636282

4. Barrow PA, Bumstead N, Marston K, Lovell MA, Wigley P. Faecal shedding and intestinal colonization of Salmonella enterica in in-bred chickens: the effect of host-genetic background. Epidemiol Infect (2004) 132:117-26. doi:10.1017/S0950268803001274

5. Withanage GS, Wigley P, Kaiser P, Mastroeni P, Brooks H, Powers C, et al. Cytokine and chemokine responses associated with clearance of a primary Salmonella enterica serovar Typhimurium infection in the chicken and in protective immunity to rechallenge. Infect Immun (2005) 73:5173-82. doi:10.1128/IAI.73. 8.5173-5182.2005

6. Setta AM, Barrow PA, Kaiser P, Jones MA. Early immune dynamics following infection with Salmonella enterica serovars Enteritidis, infantis, pullorum and Gallinarum: cytokine and chemokine gene expression profile and cellular changes of chicken cecal tonsils. Comp Immunol Microbiol Infect Dis (2012) 35:397-410. doi:10.1016/j.cimid.2012.03.004

7. Wigley P, Hulme S, Powers C, Beal R, Smith A, Barrow P. Oral infection with the Salmonella enterica serovar Gallinarum $9 \mathrm{R}$ attenuated live vaccine as a model to characterise immunity to fowl typhoid in the chicken. BMC Vet Res (2005) 1:2. doi:10.1186/1746-6148-1-2

8. Henderson SC, Bounous DI, Lee MD. Early events in the pathogenesis of avian salmonellosis. Infect Immun (1999) 67:3580-6.

9. Chappell L, Kaiser P, Barrow P, Jones MA, Johnston C, Wigley P. The immunobiology of avian systemic salmonellosis. Vet Immunol Immunopathol (2009) 128:53-9. doi:10.1016/j.vetimm.2008.10.295

10. Merrell DS, Falkow S. Frontal and stealth attack strategies in microbial pathogenesis. Nature (2004) 430:250-6. doi:10.1038/nature02760

11. Thomson NR, Clayton DJ, Windhorst D, Vernikos G, Davidson S, Churcher C, et al. Comparative genome analysis of Salmonella enteritidis PT4 and Salmonella Gallinarum 287/91 provides insights into evolutionary and host adaptation pathways. Genome Res (2008) 18:1624-37. doi:10.1101/gr.077404.108

12. Wigley P, Berchieri A Jr, Page KL, Smith AL, Barrow PA. Salmonella enterica serovar Pullorum persists in splenic macrophages and in the reproductive tract during persistent, disease-free carriage in chickens. Infect Immun (2001) 69:7873-9. doi:10.1128/IAI.69.12.7873-7879.2001

13. Kaufman J, Milne S, Gobel TW, Walker BA, Jacob JP, Auffray C, et al. The chicken B locus is a minimal essential major histocompatibility complex. Nature (1999) 401:923-5. doi:10.1038/44856 
14. Keestra AM, de Zoete MR, Bouwman LI, van Putten JP. Chicken TLR21 is an innate CpG DNA receptor distinct from mammalian TLR9. J Immunol (2010) 185:460-7. doi:10.4049/jimmunol.0901921

15. Nerren JR, Swaggerty CL, MacKinnon KM, Genovese KJ, He H, Pevzner I, et al. Differential mRNA expression of the avian-specific toll-like receptor 15 between heterophils from Salmonella-susceptible and -resistant chickens. Immunogenetics (2009) 61:71-7. doi:10.1007/s00251-008-0340-0

16. Schat KA, Kaiser P, Kaspers B. Avian Immunology. London: Elsevier (2013).

17. Withanage GS, Kaiser P, Wigley P, Powers C, Mastroeni P, Brooks H, et al. Rapid expression of chemokines and proinflammatory cytokines in newly hatched chickens infected with Salmonella enterica serovar Typhimurium. Infect Immun (2004) 72:2152-9. doi:10.1128/IAI.72.4.2152-2159.2004

18. Matulova M, Varmuzova K, Sisak F, Havlickova H, Babak V, Stejskal K, et al. Chicken innate immune response to oral infection with Salmonella enterica serovar Enteritidis. Vet Res (2013) 44:37. doi:10.1186/1297-9716-44-37

19. Iqbal M, Philbin VJ, Withanage GS, Wigley P, Beal RK, Goodchild MJ, et al. Identification and functional characterization of chicken toll-like receptor 5 reveals a fundamental role in the biology of infection with Salmonella enterica serovar Typhimurium. Infect Immun (2005) 73:2344-50. doi:10.1128/IAI.73.4. 2344-2350.2005

20. Kaiser P, Rothwell L, Galyov EE, Barrow PA, Burnside J, Wigley P. Differential cytokine expression in avian cells in response to invasion by Salmonella typhimurium, Salmonella enteritidis and Salmonella Gallinarum. Microbiology (2000) 146(Pt 12):3217-26.

21. Kogut MH, Tellez GI, McGruder ED, Hargis BM, Williams JD, Corrier DE, et al. Heterophils are decisive components in the early responses of chickens to Salmonella enteritidis infections. Microb Pathog (1994) 16:141-51. doi:10.1006/mpat.1994.1015

22. Kogut MH, Chiang HI, Swaggerty CL, Pevzner IY, Zhou H. Gene expression analysis of toll-like receptor pathways in heterophils from genetic chicken lines that differ in their susceptibility to Salmonella enteritidis. Front Genet (2012) 3:121. doi:10.3389/fgene.2012.00121

23. Chuammitri P, Ostojic J, Andreasen CB, Redmond SB, Lamont SJ, Palic D. Chicken heterophil extracellular traps (HETs): novel defense mechanism of chicken heterophils. Vet Immunol Immunopathol (2009) 129:126-31. doi:10. 1016/j.vetimm.2008.12.013

24. Kannan L, Liyanage R, Lay JO, Rath NC. Evaluation of beta defensin 2 production by chicken heterophils using direct MALDI mass spectrometry. Mol Immunol (2009) 46:3151-6. doi:10.1016/j.molimm.2009.07.005

25. Maxwell MH, Robertson GW. The avian heterophil leucocyte: a review. Worlds Poult Sci J (1998) 54:155-78. doi:10.1079/WPS19980012

26. Higgs R, Cormican P, Cahalane S, Allan B, Lloyd AT, Meade K, et al. Induction of a novel chicken toll-like receptor following Salmonella enterica serovar Typhimurium infection. Infect Immun (2006) 74:1692-8. doi:10.1128/IAI.74.3. 1692-1698.2006

27. He H, Genovese KJ, Nisbet DJ, Kogut MH. Profile of toll-like receptor expressions and induction of nitric oxide synthesis by toll-like receptor agonists in chicken monocytes. Mol Immunol (2006) 43:783-9. doi:10.1016/j.molimm.2005.07.002

28. He H, Genovese KJ, Swaggerty CL, Nisbet DJ, Kogut MH. In vivo priming heterophil innate immune functions and increasing resistance to Salmonella enteritidis infection in neonatal chickens by immune stimulatory CpG oligodeoxynucleotides. Vet Immunol Immunopathol (2007) 117:275-83. doi:10.1016/j.vetimm.2007.03.002

29. Xie H, Raybourne RB, Babu US, Lillehoj HS, Heckert RA. CpG-induced immunomodulation and intracellular bacterial killing in a chicken macrophage cell line. Dev Comp Immunol (2003) 27:823-34. doi:10.1016/S0145-305X(03) 00079-X

30. Mariani P, Barrow PA, Cheng HH, Groenen MM, Negrini R, Bumstead N. Localization to chicken chromosome 5 of a novel locus determining salmonellosis resistance. Immunogenetics (2001) 53:786-91. doi:10.1007/s00251-001-0387-7

31. Wigley P, Hulme S, Rothwell L, Bumstead N, Kaiser P, Barrow P. Macrophages isolated from chickens genetically resistant or susceptible to systemic salmonellosis show magnitudinal and temporal differential expression of cytokines and chemokines following Salmonella enterica challenge. Infect Immun (2006) 74:1425-30. doi:10.1128/IAI.74.2.1425-1430.2006

32. Wigley P, Hulme SD, Bumstead N, Barrow PA. In vivo and in vitro studies of genetic resistance to systemic salmonellosis in the chicken encoded by the SAL1 locus. Microbes Infect (2002) 4:1111-20. doi:10.1016/S1286-4579(02)01635-0
33. Fife MS, Salmon N, Hocking PM, Kaiser P. Fine mapping of the chicken salmonellosis resistance locus (SAL1). Anim Genet (2009) 40:871-7. doi:10.1111/ j.1365-2052.2009.01930.x

34. Babu US, Sommers K, Harrison LM, Balan KV. Effects of fructooligosaccharideinulin on Salmonella-killing and inflammatory gene expression in chicken macrophages. Vet Immunol Immunopathol (2012) 149:92-6. doi:10.1016/j. vetimm.2012.05.003

35. Babu US, Gaines DW, Lillehoj H, Raybourne RB. Differential reactive oxygen and nitrogen production and clearance of Salmonella serovars by chicken and mouse macrophages. Dev Comp Immunol (2006) 30:942-53. doi:10.1016/j.dci. 2005.12.001

36. Kramer J, Visscher AH, Wagenaar JA, Jeurissen SH. Entry and survival of Salmonella enterica serotype Enteritidis PT4 in chicken macrophage and lymphocyte cell lines. Vet Microbiol (2003) 91:147-55. doi:10.1016/S0378-1135(02)00304-8

37. Setta A, Barrow PA, Kaiser P, Jones MA. Immune dynamics following infection of avian macrophages and epithelial cells with typhoidal and non-typhoidal Salmonella enterica serovars; bacterial invasion and persistence, nitric oxide and oxygen production, differential host gene expression, NF-kappaB signalling and cell cytotoxicity. Vet Immunol Immunopathol (2012) 146:212-24. doi:10.1016/j.vetimm.2012.03.008

38. Withanage GS, Mastroeni P, Brooks HJ, Maskell DJ, McConnell I. Oxidative and nitrosative responses of the chicken macrophage cell line MQNCSU to experimental Salmonella infection. Br Poult Sci (2005) 46:261-7. doi:10.1080/00071660500098608

39. Jones MA, Wigley P, Page KL, Hulme SD, Barrow PA. Salmonella eInterica serovar Gallinarum requires the Salmonella pathogenicity island 2 type III secretion system but not the Salmonella pathogenicity island 1 type III secretion system for virulence in chickens. Infect Immun (2001) 69:5471-6. doi:10.1128/IAI.69.9.5471-5476.2001

40. He H, Genovese KJ, Swaggerty CL, Nisbet DJ, Kogut MH. A comparative study on invasion, survival, modulation of oxidative burst, and nitric oxide responses of macrophages (HD11), and systemic infection in chickens by prevalent poultry Salmonella serovars. Foodborne Pathog Dis (2012) 9:1104-10. doi:10.1089/fpd.2012.1233

41. Akbari MR, Haghighi HR, Chambers JR, Sharif S. Expression of antimicrobial peptide genes in chicken cecal tonsils after treatment with probiotics and challenge with Salmonella. Poult Sci (2008) 87:82-82.

42. Crhanova M, Hradecka H, Faldynova M, Matulova M, Havlickova H, Sisak F, et al. Immune response of chicken gut to natural colonization by gut microflora and to Salmonella enterica serovar Enteritidis infection. Infect Immun (2011) 79:2755-63. doi:10.1128/IAI.01375-10

43. Hasenstein JR, Lamont SJ. Chicken gallinacin gene cluster associated with Salmonella response in advanced intercross line. Avian Dis (2007) 51:561-7. doi:10.1637/0005-2086(2007)51 [561:CGGCAW]2.0.CO;2

44. Zhang G, Sunkara LT. Avian antimicrobial host defense peptides: from biology to therapeutic applications. Pharmaceuticals (Basel) (2014) 7:220-47. doi:10.3390/ph7030220

45. Bommineni YR, Pham GH, Sunkara LT, Achanta M, Zhang G. Immune regulatory activities of fowlicidin-1, a cathelicidin host defense peptide. Mol Immunol (2014) 59:55-63. doi:10.1016/j.molimm.2014.01.004

46. Alemka A, Whelan S, Gough R, Clyne M, Gallagher ME, Carrington SD, et al. Purified chicken intestinal mucin attenuates Campylobacter jejuni pathogenicity in vitro. J Med Microbiol (2010) 59:898-903. doi:10.1099/jmm.0.019315-0

47. O'Brien SJ. The "decline and fall" of nontyphoidal salmonella in the United Kingdom. Clin Infect Dis (2013) 56:705-10. doi:10.1093/cid/cis967

48. Babu U, Dalloul RA, Okamura M, Lillehoj HS, Xie H, Raybourne RB, et al. Salmonella Enteritidis clearance and immune responses in chickens following Salmonella vaccination and challenge. Vet Immunol Immunopathol (2004) 101:251-7. doi:10.1016/j.vetimm.2004.05.002

49. Okamura M, Lillehoj HS, Raybourne RB, Babu US, Heckert RA. Cell-mediated immune responses to a killed Salmonella Enteritidis vaccine: lymphocyte proliferation, T-cell changes and interleukin-6 (IL-6), IL-1, IL-2, and IFNgamma production. Comp Immunol Microbiol Infect Dis (2004) 27:255-72. doi:10.1016/j.cimid.2003.12.001

50. Desmidt M, Ducatelle R, Mast J, Goddeeris BM, Kaspers B, Haesebrouck F. Role of the humoral immune system in Salmonella Enteritidis phage type four infection in chickens. Vet Immunol Immunopathol (1998) 63:355-67. doi:10.1016/S0165-2427(98)00112-3 
51. Arnold JW, Holt PS. Response to Salmonella Enteritidis infection by the immunocompromised avian host. Poult Sci (1995) 74:656-65. doi:10.3382/ps. 0740656

52. Beal RK, Powers C, Davison TF, Barrow PA, Smith AL. Clearance of enteric Salmonella enterica serovar Typhimurium in chickens is independent of B-cell function. Infect Immun (2006) 74:1442-4. doi:10.1128/IAI.74.2.1442-1444.2006

53. Berndt A, Methner U. Gamma/delta $\mathrm{T}$ cell response of chickens after oral administration of attenuated and non-attenuated Salmonella Typhimurium strains. Vet Immunol Immunopathol (2001) 78:143-61. doi:10.1016/S01652427(00)00264-6

54. Berndt A, Pieper J, Methner U. Circulating y delta T cells in response to Salmonella enterica serovar Enteritidis exposure in chickens. Infect Immun (2006) 74:3967-78. doi:10.1128/IAI.01128-05

55. Pieper J, Methner U, Berndt A. Heterogeneity of avian gammadelta T cells. Vet Immunol Immunopathol (2008) 124:241-52. doi:10.1016/j.vetimm.2008.03.008

56. Pieper J, Methner U, Berndt A. Characterization of avian gammadelta T-cell subsets after Salmonella enterica serovar Typhimurium infection of chicks. Infect Immun (2011) 79:822-9. doi:10.1128/IAI.00788-10

57. Keestra AM, Godinez I, Xavier MN, Winter MG, Winter SE, Tsolis RM, et al. Early MyD88-dependent induction of interleukin-17A expression during Salmonella colitis. Infect Immun (2011) 79:3131-40. doi:10.1128/IAI.00018-11

58. McGeachy MJ, McSorley SJ. Microbial-induced Th17: superhero or supervillain? J Immunol (2012) 189:3285-91. doi:10.4049/jimmunol.1201834

59. Zhang L, Liu R, Song M, Hu Y, Pan B, Cai J, et al. Eimeria tenella: interleukin 17 contributes to host immunopathology in the gut during experimental infection. Exp Parasitol (2013) 133:121-30. doi:10.1016/j.exppara.2012.11.009

60. Kim WH, Jeong J, Park AR, Yim D, Kim YH, Kim KD, et al. Chicken IL-17F: identification and comparative expression analysis in Eimeria-infected chickens. Dev Comp Immunol (2012) 38:401-9. doi:10.1016/j.dci.2012.08.002

61. Min W, Kim WH, Lillehoj EP, Lillehoj HS. Recent progress in host immunity to avian coccidiosis: IL-17 family cytokines as sentinels of the intestinal mucosa. Dev Comp Immunol (2013) 41:418-28. doi:10.1016/j.dci.2013.04.003

62. Del Cacho E, Gallego M, Lillehoj HS, Quilez J, Lillehoj EP, Ramo A, et al. IL-17A regulates Eimeria tenella schizont maturation and migration in avian coccidiosis. Vet Res (2014) 45:25. doi:10.1186/1297-9716-45-25

63. Parsons BN, Humphrey S, Salisbury AM, Mikoleit J, Hinton JC, Gordon MA, et al. Invasive non-typhoidal Salmonella Typhimurium ST313 are not hostrestricted and have an invasive phenotype in experimentally infected chickens. PLoS Negl Trop Dis (2013) 7:e2487. doi:10.1371/journal.pntd.0002487

64. Chausse AM, Grepinet O, Bottreau E, Robert V, Hennequet-Antier C, Lalmanach AC, et al. Susceptibility to Salmonella carrier-state: a possible Th2 response in susceptible chicks. Vet Immunol Immunopathol (2014) 159:16-28. doi:10.1016/j.vetimm.2014.03.001

65. Berchieri A Jr, Wigley P, Page K, Murphy CK, Barrow PA. Further studies on vertical transmission and persistence of Salmonella enterica serovar Enteritidis phage type 4 in chickens. Avian Pathol (2001) 30:297-310. doi:10.1080/ 03079450120066304

66. Wigley P, Schat KA, Barrow P. The avian reprodcutive immune system. In: Schat KA, Kaiser P, Kaspers B, editors. Avian Immunology. London: Elsevier (2013). p. 265-74.

67. Michailidis G, Anastasiadou M, Froment P. Changes in the expression of tolllike receptors in response to lipopolysaccharide in chicken sertoli cells. Reprod Domest Anim (2012) 47:97-97. doi:10.1530/REP-14-0064

68. Michailidis G, Avdi M, Argiriou A. Transcriptional profiling of antimicrobial peptides avian beta-defensins in the chicken ovary during sexual maturation and in response to Salmonella Enteritidis infection. Res Vet Sci (2012) 92:60-5. doi:10.1016/j.rvsc.2010.10.010

69. Anastasiadou M, Avdi M, Michailidis G. Expression of avian beta-defensins during growth and in response to Salmonella infection in the chicken testis and epididymis. Reprod Domest Anim (2012) 47:73-73.

70. Johnston CE, Hartley C, Salisbury AM, Wigley P. Immunological changes at point-of-lay increase susceptibility to Salmonella enterica serovar Enteritidis infection in vaccinated chickens. PLoS One (2012) 7:e48195. doi:10.1371/ journal.pone.0048195

Conflict of Interest Statement: The author declares that the research was conducted in the absence of any commercial or financial relationships that could be construed as a potential conflict of interest.

Received: 19 May 2014; accepted: 20 September 2014; published online: 10 October 2014.

Citation: Wigley P (2014) Salmonella enterica in the chicken: how it has helped our understanding of immunology in a non-biomedical model species. Front. Immunol. 5:482. doi: 10.3389/fimmu.2014.00482

This article was submitted to Microbial Immunology, a section of the journal Frontiers in Immunology.

Copyright $(9) 2014$ Wigley. This is an open-access article distributed under the terms of the Creative Commons Attribution License (CC BY). The use, distribution or reproduction in other forums is permitted, provided the original author(s) or licensor are credited and that the original publication in this journal is cited, in accordance with accepted academic practice. No use, distribution or reproduction is permitted which does not comply with these terms. 